\title{
Performance evaluation of reactive direct current unbalanced magnetron sputter deposited nanostructured TiN coated high-speed steel drill bits
}

\author{
HARISH C BARSHILIA* and K S RAJAM \\ Surface Engineering Division, National Aerospace Laboratories, Bangalore 560 017, India
}

MS received 25 June 2007; revised 1 August 2007

\begin{abstract}
The stainless steels, in general, are considered to be difficult-to-machine materials. In order to machine these materials the surface of the tool is generally coated with physical vapour deposition (PVD) hard coatings such as titanium nitride (TiN), titanium aluminum nitride (TiAIN), etc. The adhesion is of vital importance for the performance of tools coated with PVD coatings. Proper surface treatments (in situ and ex situ) are required to achieve highly adherent PVD coatings on tools. We have deposited nanostructured TiN coatings on high-speed steel (HSS) drill bits and mild steel substrates using an indigenously built semi-industrial fourcathode reactive direct current (d.c.) unbalanced magnetron sputtering system. Various treatments have been given to the substrates for improved adhesion of the TiN coatings. The process parameters have been optimized to achieve highly adherent thick good quality TiN coatings. These coatings have been characterized using $\mathrm{X}$-ray diffraction, nanoindentation and atomic force microscopy techniques. The performance of the coated HSS drill bits is evaluated by drilling a $13 \mathrm{~mm}$ thick 304 stainless steel plate under wet conditions. The results show significant improvement in the performance of the TiN coated HSS drill bits.
\end{abstract}

Keywords. Semi-industrial unbalanced magnetron sputtering system; nanostructured TiN coatings; HSS d rill bits; performance evaluation.

\section{Introduction}

Stainless steels are considered to be difficult to machine materials. Built-up edge and irregular wear situations are often faced in machining operations of these materials (Trent and Wright 2000). Difficulties from the machining point of view increase when high-strength stainless steels are to be machined. During drilling, the chips rotate with the drill and impact the hole-wall or interior of the flute, thus affecting the performance of the drill bits. Drilling is one of the most demanding machining processes. Because the completely machined geometry and the surface are generated in one operation and usually post-machining is impossible. The demands with regard to diameter precision, straightness and surface quality are enormously high. Tools must meet the requirements for diameter tolerances and shape-position tolerances.

In recent years, there have been considerable advances in the development of hard and wear-resistant coatings for applications in the field of cutting tools and other moving parts to improve durability (Stappen et al 1995). Transition metal nitrides such as titanium nitride (TiN), chromium nitride $(\mathrm{CrN})$ and titanium-aluminum nitride

\footnotetext{
*Author for correspondence (harish@css.nal.res.in)
}

(TiAlN) have been widely used as protective hard coatings to increase the lifetime and performance of the cutting and forming tools (Horling et al 2005; Reiter et al 2006; Endrino et al 2006). These coatings have also shown their ability to improve the corrosion resistance of a variety of steel substrates (William Grips et al 2006). Addition of $\mathrm{Al}$ into TiN (or $\mathrm{CrN}$ ) has been shown to improve the oxidation resistance of transition metal nitrides considerably (Barshilia and Rajam 2004a; Barshilia et al 2005, 2006). The structure and properties of TiN have been studied in detail by several researchers. These coatings have been prepared by different techniques and sputtering is one of the most successful techniques. There are several review papers on the structure and properties of TiN coatings (see for example, Hultman et al 1999; Hultman 2000). The application of titanium nitride films on high-speed steels (HSS) with different physical vapour deposition (PVD) techniques is today a well-established technology. Application of hard coating on the tool prevents the material build up and ensures that the quality of the drilling operation is significantly better than with the uncoated tool with regard to diameter precision and surface roughness. The surface of the coated tool supports the chip removal. The chip moves over the coating and can be quickly removed, thereby preventing jamming of the drill bit during operation. Tools coated with TiN often exhibit 
an increase in tool life by several hundred percent compared to similar uncoated tools (D'Errico et al 1999). In spite of this successful application of TiN on cutting tools, the understanding of how the wear of the tools is influenced by the composition, structure, adhesion and mechanical properties of the film and the substrate is not very well known.

In this paper, we have deposited nanostructured TiN coatings on high speed steel drill bits using an indigenously developed cost effective semi-industrial reactive direct current unbalanced magnetron sputtering process. In order to achieve dense and defect free TiN coatings, we have used asymmetric-bipolar pulsed d.c. generators (Barshilia and Rajam 2006). The performance of these coated drill bits was evaluated by drilling a stainless steel (304) plate under wet conditions. These results are compared with the uncoated HSS drill bits.

\section{Experimental}

\subsection{Substrate material}

The tool substrates used were HSS drill bits consisting of $1.26 \mathrm{wt} \% \mathrm{C}, 4.35 \mathrm{wt} \% \mathrm{Cr}, 2.67 \mathrm{wt} \% \mathrm{~V}, 81.82 \mathrm{wt} \% \mathrm{Fe}$, $4.00 \mathrm{wt} \%$ Mo and $5.90 \mathrm{wt} \% \mathrm{~W}$. The composition of the substrate was determined using energy dispersive X-ray analysis (EDAX). The drill bits were ground to a final surface roughness of the order of $0.3 \mu \mathrm{m}$. Metallographically polished mild steel discs were also coated for the coating characterization.

\subsection{Substrate cleaning}

2.2a Solvent cleaning: The high speed steel drill bits were cleaned in an ultrasonic agitator using commercial cleaning solutions, Rodaweg Co Super and Galvex Unic Neutra, to remove oils, residues and for protection against corrosion. First the HSS drill bits were cleaned using a mixture of $3 \%$ Rodaweg solution and $97 \%$ distilled water in an ultrasonic bath for $5 \mathrm{~min}$. After this the drill bits were rinsed in distilled water for $1 \mathrm{~min}$. Then the substrates were cleaned using 1\% Galvex solution mixed with 99\% distilled water in an ultrasonic agitator for 3-4 min. Once again the drill bits were rinsed in distilled water for $1 \mathrm{~min}$. Subsequently, the drill bits were kept in ultrasonic bath in distilled water for $2 \mathrm{~min}$. Finally, the drill bits were dried with dry nitrogen before keeping them in the vacuum chamber.

2.2b Plasma treatment: Generally, ultrasonically cleaned metal substrates (such as HSS drill bits) contain oxide layer as the contamination layer. In order to remove this oxide layer, an in situ plasma treatment with hydrogen and argon was used at a discharge voltage of $-700 \mathrm{~V}$. In this process, the contaminants can be broken down due to highly energetic particle $\left(\mathrm{Ar}^{+}\right)$. Furthermore, the metallic oxide reacts with hydrogen and gets reduced in an oxide free surface. We used in situ plasma treatments consisting of $\mathrm{Ar}+\mathrm{H}_{2}$ plasma and Ar plasma for $1 \mathrm{~h}$ duration each after a proper substrate cleaning procedure. These treatments removed all the impurities present on the drill bits.

\subsection{Coating deposition}

We have indigenously designed and developed a cost effective semi-industrial four-cathode reactive direct current unbalanced magnetron sputtering system which can deposit nitride, oxide, carbide and metallic coatings at high growth rates with good uniformity. The schematic diagram of the sputtering system is shown in figure 1 . The effective plasma volume of the sputtering system is $7 " \times 7 " \times 7$ ". The sputtering system essentially consists of: (i) $760 \mathrm{~mm}$ diameter, $600 \mathrm{~mm}$ cylindrical double walled water-cooled vacuum chamber with a number of ports, which act as sputtering chamber. It houses all the magnetron cathodes, substrate holder, etc, (ii) high vacuum pumping system with $900 \mathrm{l} / \mathrm{s}$ capacity turbo-molecular pump backed by a direct drive double stage rotary vacuum pump, valves, pipeline, vacuum measuring gauges, etc (iii) four direct cooled unbalanced magnetron cathodes with feed-throughs mounted horizontally in opposedcathode configuration suitable for co-sputtering, (iv) four $5 \mathrm{~kW}$ asymmetric-bipolar pulsed plasma generators to power 7.25" diameter unbalanced magnetron cathodes, (v) substrate holder plate for mounting three-dimensional objects with planetary rotation and heating facility, (vi) $1.5 \mathrm{~kW}$ d.c. power supply for substrate bias and ion bombardment, (vii) control console for mounting separately the vacuum chamber, the electrical instruments and the control instruments, (viii) capacitance manometer, throttle valves, planetary rotation of the substrate, mass flow controller, etc and (ix) standard system precaution and protections.

In order to deposit nanostructured TiN coatings, four $\mathrm{Ti}$ (purity $=99.95 \%$ ) targets were sputtered in high purity Ar (99.999\%) and $\mathrm{N}_{2}$ (99.999\%) plasma. The coatings were deposited under a base pressure of $2 \times 10^{-4} \mathrm{~Pa}$ and a total $\mathrm{Ar}+\mathrm{N}_{2}$ gas pressure of $4 \times 10^{-1} \mathrm{~Pa}$. The flow rates of $\mathrm{N}_{2}$ and Ar were controlled separately by mass flow controllers. The substrate to target distance was $\sim 7.6 \mathrm{~cm}$. A d.c. substrate bias of $-75 \mathrm{~V}$ was applied to improve the mechanical properties of the coatings and also to control the crystallite size of the coatings. The pulsed generators were operated at the following conditions: frequency $=$ $100 \mathrm{kHz}$, pulse width $=2976 \mathrm{~ns}$, duty cycle $=30 \%$ and reverse bias voltage $=+37 \mathrm{~V}$ (Barshilia and Rajam 2006). The coatings were deposited at a substrate temperature of $350^{\circ} \mathrm{C}$. For all the experiments, the power density was $\sim 1.8 \mathrm{~W} / \mathrm{cm}^{2}$ for each Ti target. About $0.5 \mu \mathrm{m}$ thick Ti interlayer was deposited for all the samples to improve 


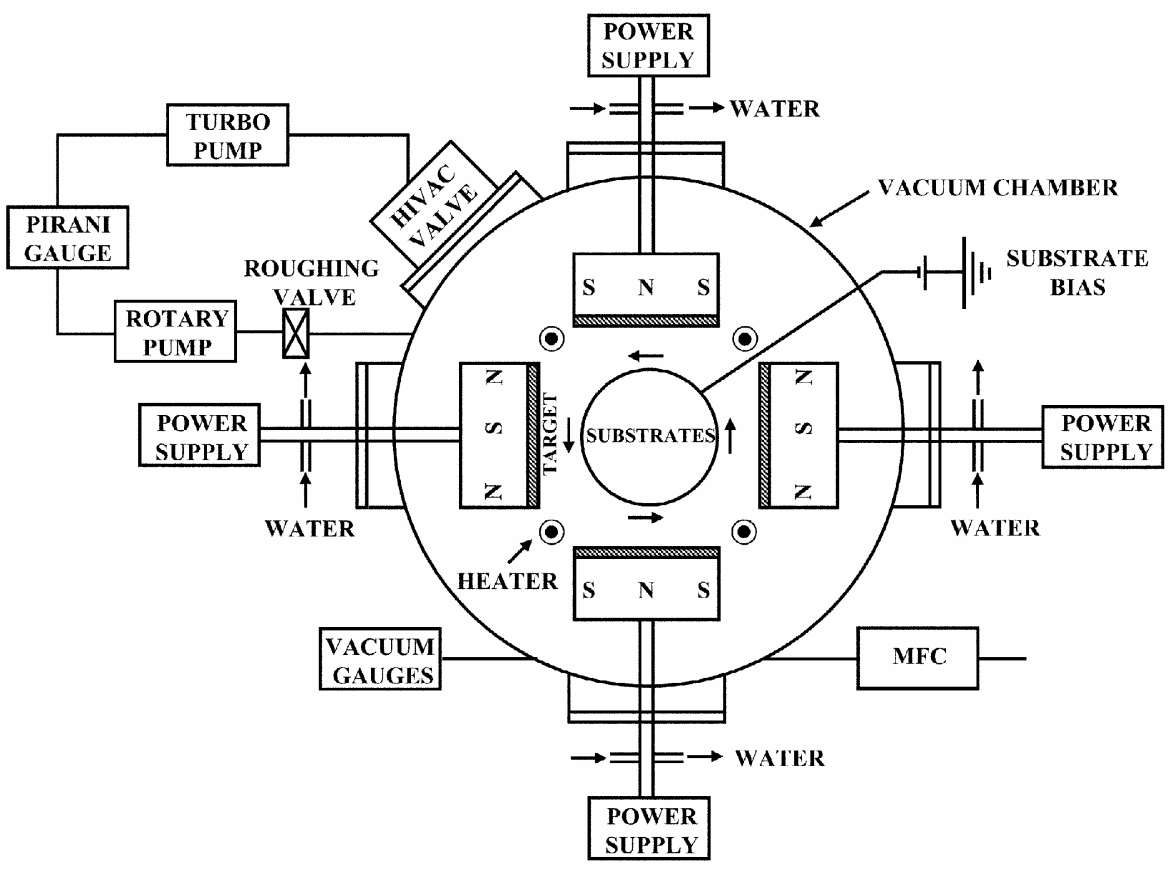

Figure 1. Schematic diagram of the four-cathode reactive direct current unbalanced magnetron sputtering system.

Table 1. Typical process parameters for the deposition of TiN coatings.

\begin{tabular}{|c|c|c|}
\hline Step & Process & Parameters \\
\hline 1. & Substrate cleaning in $\mathrm{Ar}+\mathrm{H}_{2}$ plasma & $\begin{array}{l}\text { Substrate bias }=-700 \mathrm{~V}, \text { Ar flow rate }=5 \mathrm{sccm}, \mathrm{H}_{2} \text { flow rate }=12 \mathrm{sccm} \text {, } \\
\text { pressure }=6 \times 10^{-1} \mathrm{~Pa} \text {, duration }=1 \mathrm{~h}\end{array}$ \\
\hline 2. & Substrate cleaning in Ar plasma & $\begin{array}{l}\text { Substrate bias }=-700 \mathrm{~V}, \text { Ar flow rate }=35 \mathrm{sccm} \text {, pressure }=4 \times 10^{-1} \mathrm{~Pa} \text {, } \\
\quad \text { duration }=1 \mathrm{~h}\end{array}$ \\
\hline 3. & Ti interlayer & $\begin{array}{l}\text { Power }=250 \text { watts to each target, substrate bias }=-125 \mathrm{~V}, \text { Ar flow } \\
\text { rate }=35 \mathrm{sccm}, \text { pressure }=1 \times 10^{-1} \mathrm{~Pa} \text {, substrate temperature }=350^{\circ} \mathrm{C}, \\
\text { deposition time }=45 \mathrm{~min} \text {, thickness }=0.5 \mu \mathrm{m}\end{array}$ \\
\hline 4. & TiN deposition & $\begin{array}{l}\text { Nitrogen flow rate }=15 \mathrm{sccm} \text {, argon flow rate }=35 \mathrm{sccm} \text {, pressure }= \\
\quad 1 \times 10^{-1} \mathrm{~Pa} \text {, substrate bias }=-75 \mathrm{~V} \text {, substrate temperature }=350^{\circ} \mathrm{C} \\
\text { Ti: Power }=500 \text { watts to each targets } \\
\text { Deposition time }=5 \mathrm{~h} \\
\text { Thickness of the coating }=4 \mu \mathrm{m}\end{array}$ \\
\hline 5. & Cooling down and venting & $45 \mathrm{~min}$ \\
\hline
\end{tabular}

the adhesion of the coatings. The process parameters were first optimized to achieve $\mathrm{B} 1 \mathrm{NaCl}$ structure of TiN. For this, films were deposited at various nitrogen flow rates, sputtering power levels, substrate bias, substrate temperature, etc. The optimized deposition conditions are listed in table 1. Figure 2 shows the photograph of the nanostructured TiN coated HSS drill bits deposited in the system.

\subsection{Coating characterization}

2.4a X-ray diffraction: XRD patterns of the coatings in thin film mode (off-set angle $=2^{\circ}$ ) were recorded in a
Rigaku D/max 2200 Ultima X-ray powder diffractometer. The X-ray source was a $\mathrm{CuK}_{\alpha}$ radiation $(\lambda=0 \cdot 15418 \mathrm{~nm})$, which was operated at $40 \mathrm{kV}$ and $40 \mathrm{~mA}$.

2.4b Nanoindentation hardness: The hardness measurements were performed in a nanoindenter (CSEM Instruments) at a load of $5 \mathrm{mN}$ using a Berkovich diamond indenter. At this load the indentation depth was much less than $1 / 10$ th of the film thickness, thus virtually eliminating the effect of substrate on the hardness measurements. Ten indentations were made on the sample and the values reported herein represent the average of ten values. Root mean square roughness $\left(R_{\mathrm{a}}\right)$ of the films at different places was measured by atomic force micro- 
scopy (AFM). The AFM (surface imaging systems) was operated in non-contact mode.

\subsection{Testing method}

Drilling tests were carried out using an automated Oerlikon make radial drilling machine. Figure 3 shows the photograph of the drilling operation. With TiN coated HSS drill bits, 25 holes were drilled on a $13 \mathrm{~mm}$ thick SS 304 plate to determine the tool life and performance of the coated drills. After drilling operation, the TiN coating

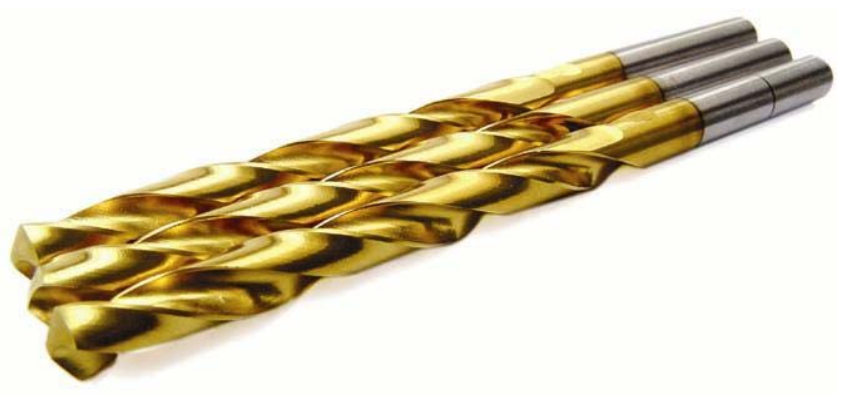

Figure 2. Photograph of the TiN coated HSS drill bits.

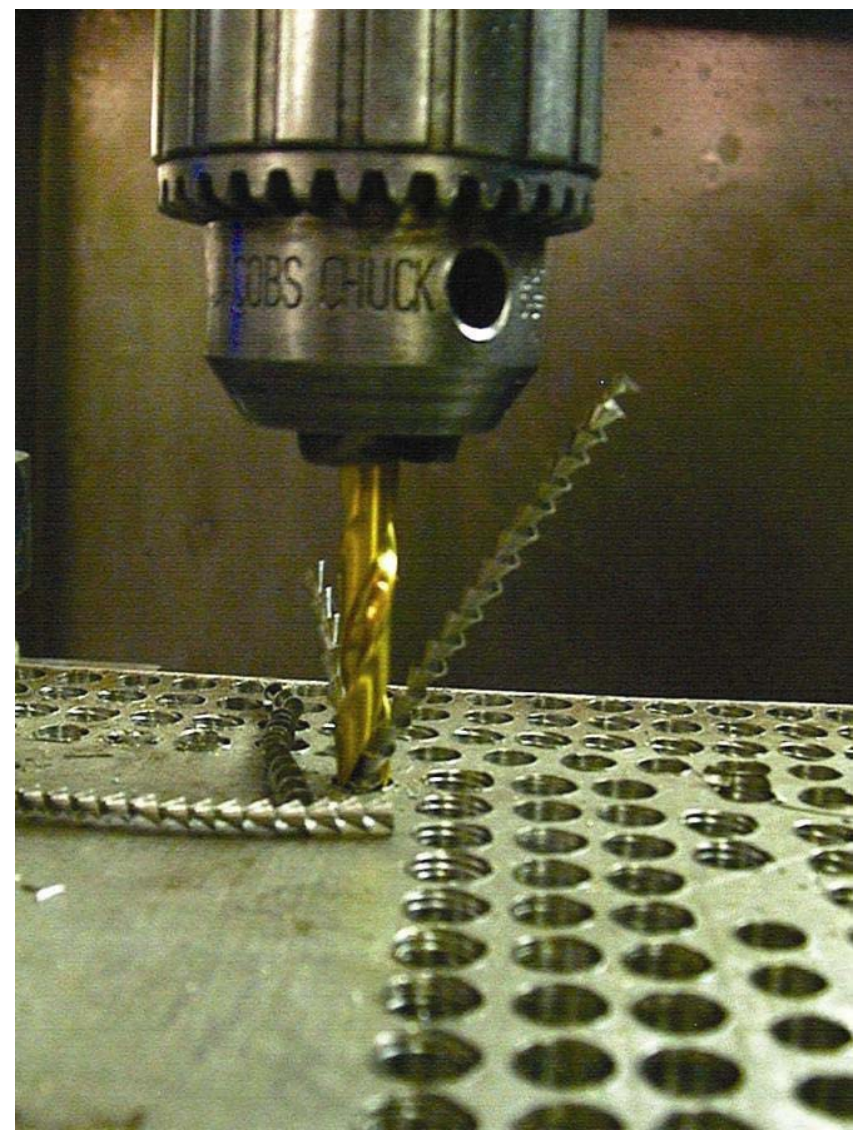

Figure 3. Photograph of the TiN coated HSS drill bit during drilling operation, showing continuous flow of chips. on the margins, cutting edges and lips of the drills was observed through an optical microscope (magnification $=$ $10 \times$ ). The standard parameters for testing are summarized in table 2. Several TiN coated HSS drill bits were used for these tests. The uncoated drill bits were also tested under similar conditions but only 10 holes could be drilled in the uncoated drill bits. The uncoated drill bits were also examined under optical microscope before and after testing.

\section{Results and discussion}

\subsection{Cross-sectional studies}

For the measurement of coating thickness a mild steel disc was also kept along with the HSS drill bits during deposition. This substrate was used for the cross-sectional studies. A $100 \mu \mathrm{m}$ thick copper backing layer was provided on top of the TiN coating. The samples were cut and polished metallographically to see the cross-section. Figure 4

Table 2. Standard parameters for testing.

\begin{tabular}{ll}
\hline Machine & Oerlikon radial drilling machine \\
Drill & $7 \mathrm{~mm}$ diameter, HSS \\
Coating & TiN \\
No. of holes & 25 \\
Material to be tested & Stainless steel $304(280 \mathrm{HV})$ \\
Thickness of the material & $13 \mathrm{~mm}$ \\
Cutting speed & $10 \mathrm{~m} / \mathrm{min}$ \\
Feed rate & $0 \cdot 06 \mathrm{~mm} /$ revolution \\
Tool speed & $400 \mathrm{RPM}$ \\
Point angle of drill & $118-120^{\circ}$ \\
Helix angle of flutes & $28-30^{\circ}$ \\
Cooling media & Soluble oil with water \\
\hline
\end{tabular}

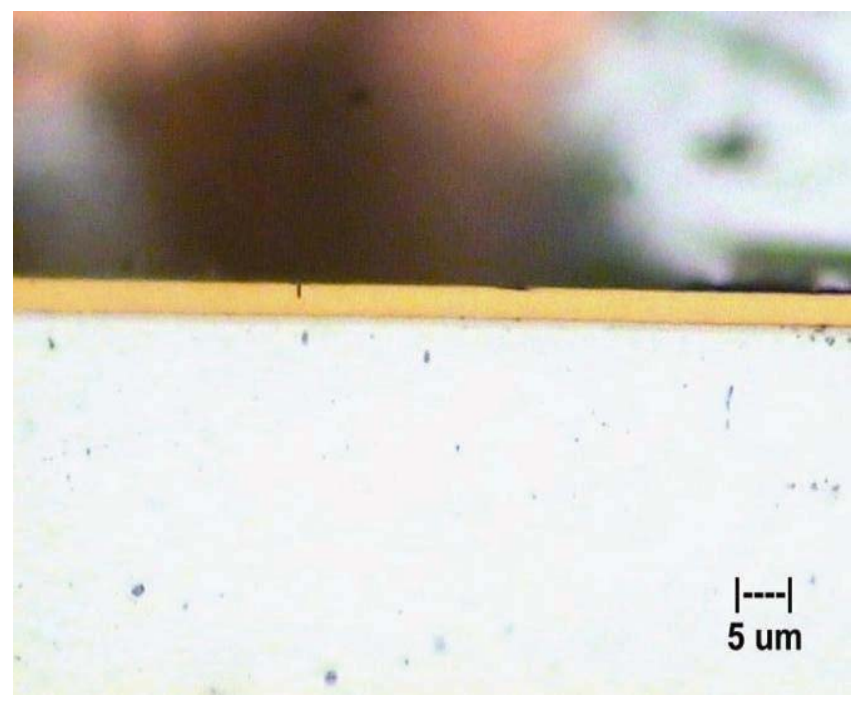

Figure 4. Cross-section of a nanostructured TiN coating deposited on steel disc. 
shows a typical cross-section of a TiN coating deposited for $5 \mathrm{~h}$ and the total thickness of the coating is $\sim 4 \mu \mathrm{m}$ and the growth rate is $\sim 0.8 \mu \mathrm{m} / \mathrm{h}$. From the photograph, it is clear that the TiN coating is adherent and uniform.

\section{$3.2 X$-ray diffraction data}

The stoichiometric phase of $\mathrm{TiN}$ with $\mathrm{B} 1 \mathrm{NaCl}$ structure exists only in a limited range of nitrogen concentration (Toth 1971). Therefore, the process parameters were first optimized by varying the nitrogen partial pressure, target power, substrate temperature, operating pressure and substrate bias. The XRD pattern of a typical TiN coating deposited under the optimized experimental conditions (see table 1), used in the present study, is shown in figure 5 . The high intensity peak centred at $2 \theta=36.38^{\circ}$ is assigned to cubic TiN (111) reflection and the peak with a low intensity at $2 \theta=42.51^{\circ}$ is assigned to cubic TiN (200) reflection. Other higher angle reflections such as (220) and (311) were very weak, indicating polycrystalline nature of the coating. The XRD data, thus, confirms the formation of $\mathrm{B} 1 \mathrm{NaCl}$ structure. The XRD data showed that the average crystallite size of the TiN coating was $\sim 7-8 \mathrm{~nm}$, indicating its nanocrystalline behaviour. The composition of the TiN coating was analysed using EDAX and is presented in table 3 .

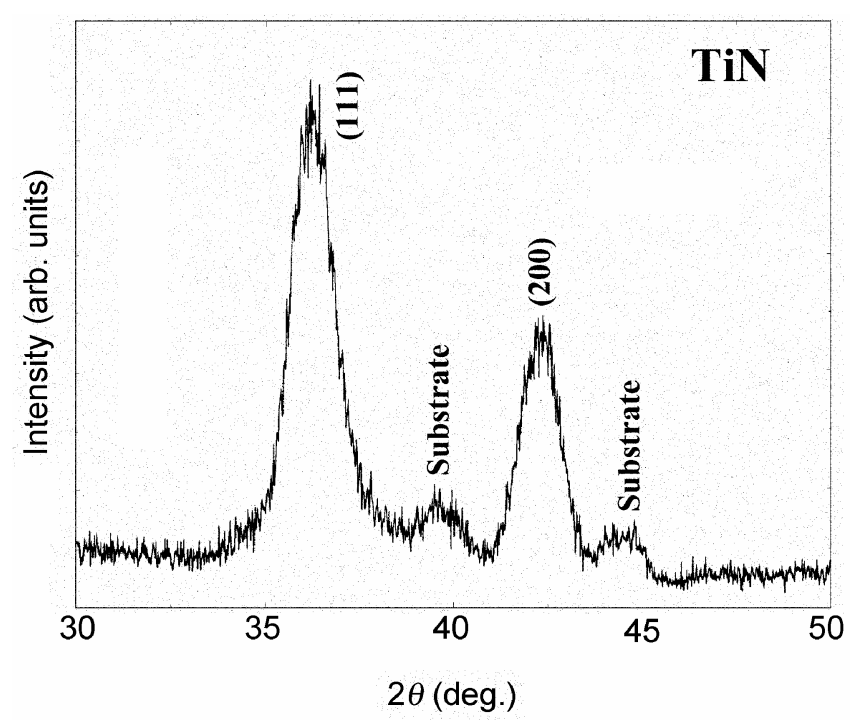

Figure 5. XRD data of the TiN coating deposited on steel substrate.

Table 3. Composition of TiN coating, as determined using EDX analysis.

\begin{tabular}{ccccc}
\hline & Ti (at.\%) & N (at.\%) & Ar (at.\%) & O (at.\%) \\
\hline TiN & 71.22 & 28.05 & 0.33 & 0.40 \\
\hline
\end{tabular}

\subsection{Nanoindentation data}

Typical load vs displacement curve for a TiN coating deposited on to a steel disc under optimized conditions is shown in figure 6 . The maximum indentation depth was $90 \mathrm{~nm}$, which is less than $1 / 10$ th of the coating thickness $(\sim 4 \mu \mathrm{m})$. After initial contact of the indenter on surface, the load was increased at a predetermined rate $(10 \mathrm{mN} / \mathrm{min})$ to the desired maximum load $(5 \mathrm{mN})$ and then decreased at the same rate $(10 \mathrm{mN} / \mathrm{min})$ to zero. The unloading curve followed the partial elastic recovery of the sample material. The details about nanoindentation measurements are described elsewhere (Barshilia and Rajam 2002). From the load vs displacement plot, the hardness of TiN coating was calculated and it was found to be $\sim 2800 \mathrm{~kg} / \mathrm{mm}^{2}$. These coatings were also characterized using atomic force microscopy. The roughness of the sample was measured at several places by AFM. Threedimensional AFM images of a typical nanostructured TiN coating deposited on to a steel disc at three different places are shown in figure 7 . The coating exhibited a root mean square roughness of 3-4 $\mathrm{nm}$.

The effect of process parameters on the mechanical properties and surface roughness of TiN coatings, deposited under almost similar conditions, is described in our previous paper (Barshilia and Rajam 2004b). In general, hardness and surface roughness depend critically on the substrate bias. The hardness increases and the surface roughness decreases with an increase in the substrate bias. The increase in the hardness of the coatings is attributed to a decrease in the crystallite size (e.g. 15 and $7 \mathrm{~nm}$ at 0 and $-75 \mathrm{~V}$ bias, respectively). Similarly, small

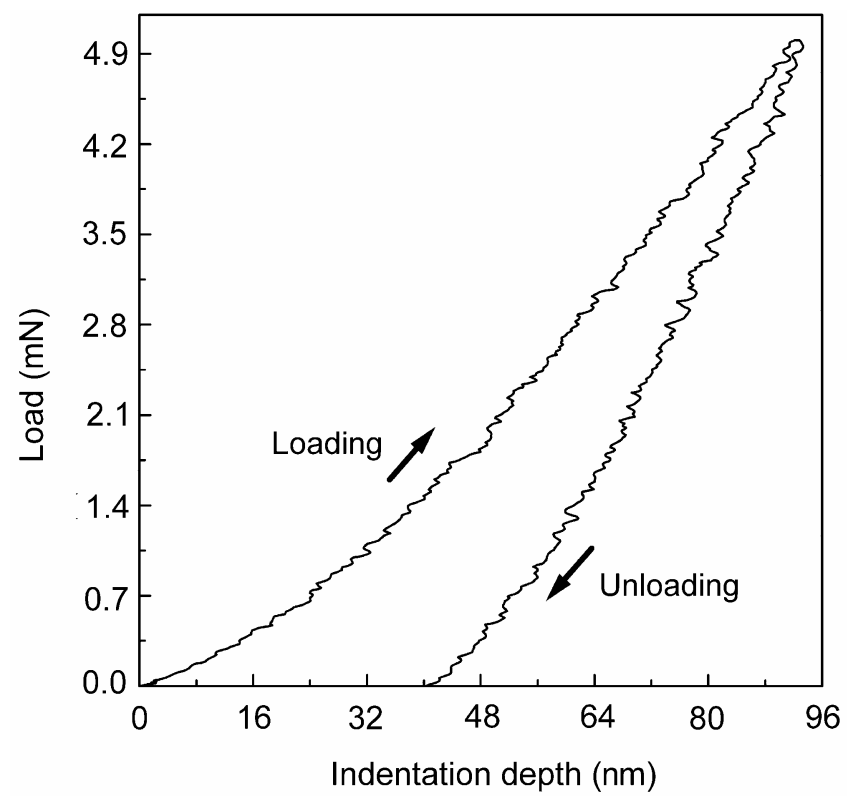

Figure 6. Load vs displacement curve of nanoindentation data for a $4 \mu \mathrm{m}$ thick TiN coating deposited on steel disc. 


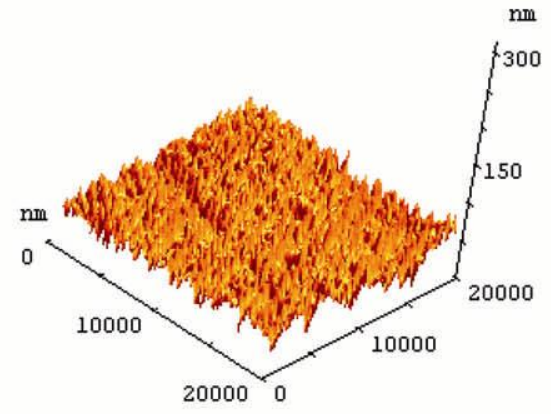

(a)

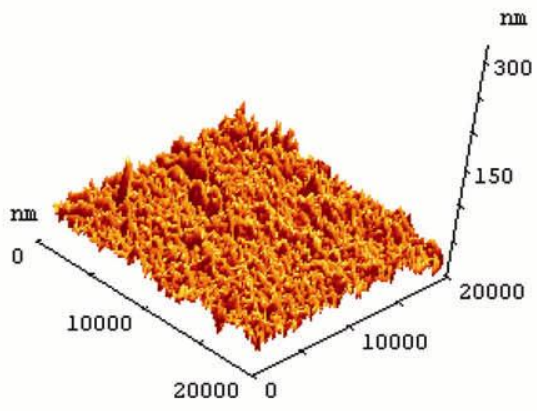

(b)

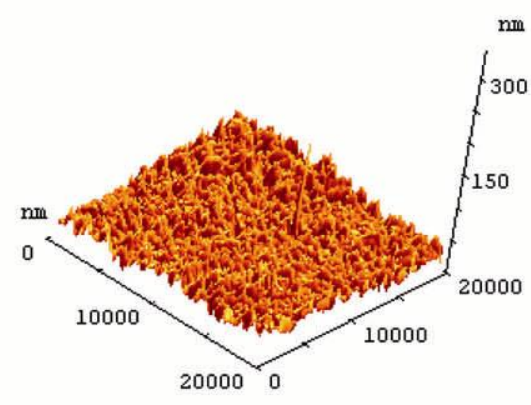

(c)

Figure 7. AFM data of a typical TiN coating deposited on steel disc at three different places.
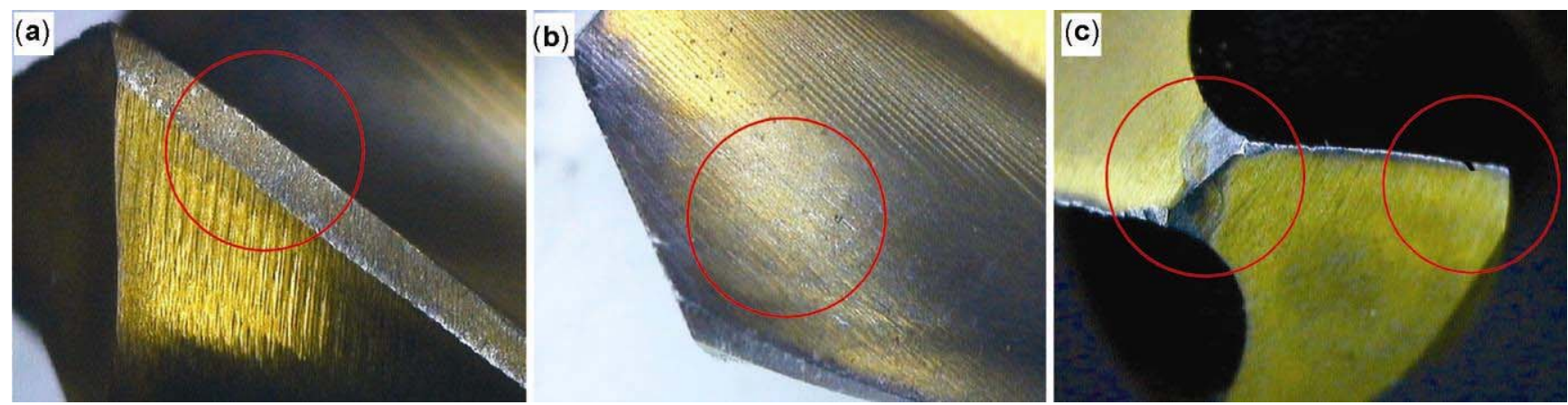

Figure 8. Photographs of the TiN coated HSS drill bits after testing: a. TiN coating intact on cutting edge (land), b. less wear on the flutes and c. less wear on lip and chisel edge.

crystallite size is believed to be responsible for smooth surface morphology of the coating deposited at higher substrate bias voltages.

\subsection{Performance evaluation of TiN coated HSS drill bits}

For optimum results, before testing the drills, the tool geometry was kept identical and standard parameters were maintained for the drilling operation. The TiN coating keeps the cutting edge smooth and blemish free. It also prevents material build up and ensures that the quality of the drilling operation (with respect to diameter precision and surface roughness) is significantly better than with uncoated drill bits. TiN coating reduces friction and allows smoother chip flow and chip curls. The chips slide over the coated flutes easily, which are removed quickly. These factors reduce the amount of sub-surface strain going into the tool material and increase the tool life.

Several performance evaluation measurements were done to evaluate the performance of TiN coated drill bits. Figure 8 shows the photographs of TiN coated HSS drill bits after testing. When drilling stainless steel, the built up edge is either absent or is very small with TiN coated drill bits. The surface finish is greatly improved by elimination of built up edge with the TiN coated drill bit. As clearly seen from the photograph, the TiN coating on the margins and cutting edges was intact and less wear was observed on the flutes. Similarly, less wear was observed on the lip and the chisel edge. It was possible to effectively overcome the formation of material build up on the area of the cutting edge and smoother flow of the chip over the coated flutes. The quality of the drilled hole was significantly better than uncoated drill bits. The surface finish, diameter precision of the hole, reduced material build up on the cutting edges and finally increased tool life were obtained with TiN coated HSS drill bits. The material build up on the margin of the drill bit leads to poor surface finish of the drilled hole. The variation of the average roughness of the drilled holes with TiN coated HSS drill bit is shown in figure 9, indicating a minimal change in the surface roughness of the drilled holes.

\subsection{Performance evaluation of uncoated HSS drill bits}

With uncoated drill bits, only 10 holes could be drilled. Figure 10 shows the photographs of the uncoated drill bit before and after testing. The uncoated drill bit clearly showed rounding off at the cutting edges, margins and lips, this led to chipping of the material on the breakthrough side and material build up on the margin of the 
drill bit. These factors resulted in a poor surface finish of the drilled holes and jamming of the drill bit in the holes. Hence, the drill bit was taken out of the drilling process.

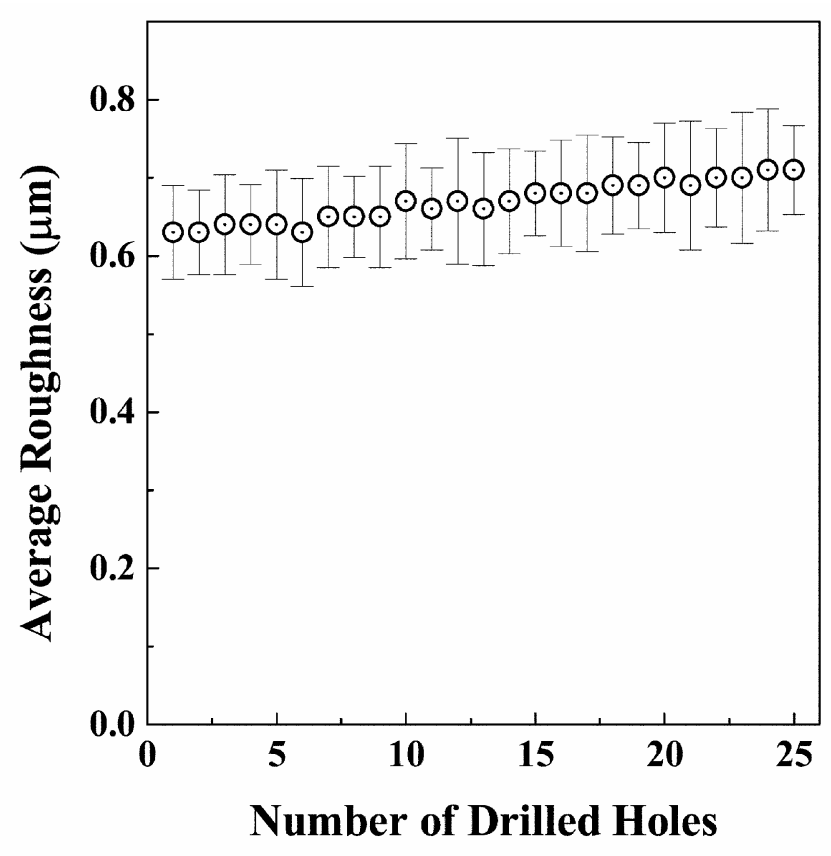

Figure 9. Roughness of the drilled holes with TiN coated HSS drill bits.

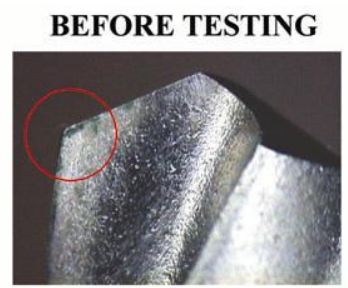

(a)

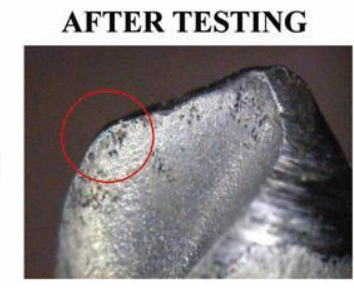

SHARP CUTTING EDGES

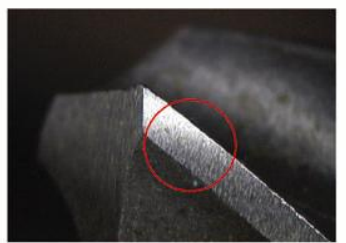

(b)

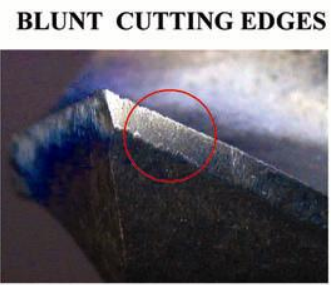

SHARP MARGIN

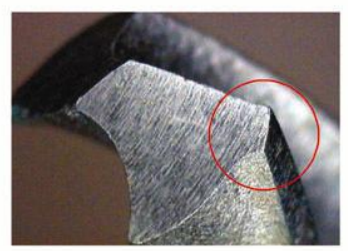

(c)
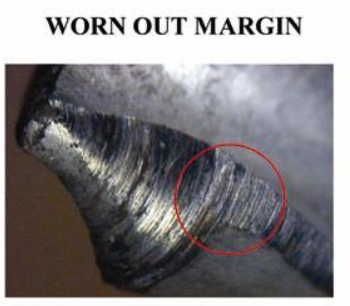

SHARP LIP AND CUTTING EDGE BLUNT LIP AND CUTTING EDGE

Figure 10. Photographs of uncoated HSS drill bits before and after testing.
Furthermore, with uncoated drill bit it was not possible to effectively overcome the formation of material build up on the area of the cutting edge.

The results presented herein indicate that the performance of the nanostructured TiN coated drill bits was very high as compared to the uncoated drill bits. The high performance of pulsed sputter deposited nanostructured TiN coatings is attributed to dense microstructure, high hardness and improved adhesion.

\section{Conclusions}

About $4 \mu \mathrm{m}$ thick TiN coatings were prepared using an indigenously built cost effective semi-industrial reactive direct current unbalanced magnetron sputtering system on commercially available high speed steel drill bits and also on mild steel discs. Various treatments were given to the substrates for achieving highly adherent and uniform TiN coatings. Studies indicated that plasma treatment consisting of $\mathrm{H}_{2}$ and Ar improved the adhesion of the coatings significantly. The process parameters were optimized to achieve highly adherent good quality TiN coatings. The $\mathrm{X}$-ray diffraction data showed the formation of a single phase nanocrystalline $\mathrm{TiN}$ with $\mathrm{Bl} \mathrm{NaCl}$ structure. The nanoindentation data indicated that these coatings exhibited a hardness of $2800 \mathrm{~kg} / \mathrm{mm}^{2}$. The performance of the TiN coated drill bits was evaluated by drilling holes in a $13 \mathrm{~mm}$ thick SS304 plate. The results indicated significant enhancement in the performance of the TiN coated HSS drill bits.

\section{Acknowledgements}

This work was supported by CSIR Networked Projects on 'Developing and sustaining high science technology for National Aerospace Programs, under the Project No. I888-1/37. We thank Mr Jakeer Khan, Mr Praveen Kumar, Mr Manjunatha, Mr V Kartik and Mr Yogesh for their technical assistance during the commissioning and installation of the sputtering system and for the sample preparation.

\section{References}

Barshilia H C and Rajam K S 2002 Surf. Coat. Technol. 155 195

Barshilia H C and Rajam K S 2004a Bull. Mater. Sci. 2735

Barshilia H C and Rajam K S 2004b J. Mater. Res. 11 3196

Barshilia H C and Rajam K S 2006 Surf. Coat. Technol. 201 1827

Barshilia H C, Surya Prakash M, Jain A and Rajam K S 2005 Vacuum 77169

Barshilia H C, Selvakumar N, Deepthi B and Rajam K S 2006 Surf. Coat. Technol. 2012193 
D’Errico G E, Guglielmi E and Rutelli G 1999 J. Mater. Proc. Technol. 92-93 251

Endrino J L, Fox-Rabinovich G S and Gey C 2006 Surf. Coat. Technol. 2006840

Horling A, Hultman L, Oden M, Sjolen J and Karlsson L 2005 Surf. Coat. Technol. 191384

Hultman L 2000 Vacuum 571

Hultman L, Engstroem C, Birch J, Johansson M P, Oden M, Karlsson L and Ljungcrantz H 1999 Zeitschrift fur Metallkunde 90803
Reiter A E, Brunner B, Ante M and Rechberger J 2006 Surf. Coat. Technol. 2005532

Stappen M V, Stals L M, Kerkhofs M and Quaeyhaegens C 1995 Surf. Coat. Technol. 74-75 629

Toth L E 1971 Transition metal carbides and nitrides (New York: Academic Press)

Trent E M and Wright P K 2000 Metal cutting (Heinemann, USA: Butterworth) 4th ed.

William Grips V K, Barshilia H C, Ezhil Selvi V and Rajam K S 2006 Thin Solid Films 514204 